\title{
Correlation between slow vital capacity and the maximum phonation time in healthy adults ${ }^{1}$
}

Yossef Aelony ${ }^{(1)}$

Marco Aurélio de Valois Correia Junior(2)

(1) Harbor UCLA, Torrance, California, USA. (2) Universidade de Pernambuco - UPE, Petrolina, PE, Brasil.

Conflict of interest: non-existent

This document does not have translation.

Received on: May 25, 2016 Accepted on: July 05, 2016

Mailing address: Marco Aurélio de Valois Correia Junior Rua Luiz Guimarães, n-411, Apto-301-a Poço da Panela, Recife-PE, Brasil CEP:-52061-160

E-mail:marcovalois@gmail.com

\section{Dear Scientific Editor of Revista CEFAC}

I am very interested in an important research published earlier 2014 on the Correlation between slow vital capacity (VC) and maximum phonation time (MPT) ${ }^{1}$. I have been using these tests informally since the 1960s, when Robert Olsen presented his data in a handout for resident physicians at the Wadsworth VA Hospital in West Los Angeles. I do not believe he formally published his work as neither google nor his colleagues of that period are aware of it. He did publish his Match test study in $1962^{2}$. Unfortunately, Dr. Olsen passed away in 1973.

I have not found normal predicted values for these tests to be particularly necessary since I practice in a large metropolitan area. However, these tests are very useful in certain circumstances, as you outlined. Recently, I find them very helpful in treating tuberculosis patients, who are recovering from parenchymal disease, airway disease, or pleural effusions. They are helpful in trending progress (or occasionally failure to progress or decline) which psychologically benefits the patient who is required to take medication for months or years. In addition, it supports the physician who cannot use formal testing due to the fear of spreading the disease.

I do have some questions \& comments:

1. I wonder if you will or have tested patients in more than one language. The counting result might be variable while the phonation test should be the same.

2. The normal values found by Dr. Olsen were counting in English to $100+/-20$ in normal physician volunteers, all of whom were likely Caucasian, male, young $\&$ at that time the average height of a man was $178 \mathrm{~cm}$ (very close to your value). The minimum MPT was 18 seconds.

3. We have found that Asians and Afro-Americans tend to have SVC, Forced expiratory volume (FEV) values between 85 \& 90\% of Crapo's ${ }^{3,4}$ values for Caucasians, but these adjustments are probably not important for trending or 
estimating since values to determine disability would need be determined on precise instruments. I don't recall how broad-cultural Brazilian values compare to Crapo $^{3,4}$.

4. Another issue relates to vocal cord function. Young people generally have normal VC function. However, I have developed presbyvocalis with aging with weak muscles of phonation, which prevents full closure. I imagine the quantum of air per second is related to the space between the cords. In my own case, I can only phonate for 16 seconds, but can count to 100 or more. In older patients, therefore, it might be wise to do both tests.

Once again, congratulations for your fascinating study. I would be delighted to read your comments.

\section{Sincerely,}

Yossef Aelony, M.D., F.A.C.P., F.C.C.P.

Clinical Professor of Medicine

Division of Respiratory \& Critical Care Medicine \& Physiology

Harbor-UCLA

Kaiser Permanente - Harbor City

LA County per diem TB Clinician

Board of Directors of Breathe Los Angeles

TB Clinician for the city of Long Beach

City of Long Beach Health Department 2525 Grand

Ave., Long Beach, CA 90815, suite 167.

email: y.aelony@cox.net

\section{Authors' response}

We were very excited about your considerations and thank you for your comments and questions. Unfortunately, I did not have knowledge of Dr. Olsen Match test study, which since 1960 had been studying this subject. A good part of my time, I have devoted to researching this topic in recent years. In 2014, we published an article 5 that may be of your interest carried out in hospitalized individuals: "use of the technique of counting numbers as a predictor of slow vital capacity in hospitalized Individuals". Another paper was published in $2013^{6}$ but unfortunately only in Portuguese. We are trying to evaluate these tests in different conditions such as neuromuscular patients and think that tuberculosis would be an excellent idea to evaluate these patients and observe a possible decline depending on their functional limitations.
Regarding your questions, we will be happy to try to answer them.

1. I wonder if you will or have tested patients in more than one language. The counting result might be variable while the phonation test should be the same.

These tests were conducted in Brazilian university students and were not made in other languages. From what I have observed, we have not seen studies using the MPT to assess lung function as the research proposal, although it has already been done for other purposes, mainly to evaluate the glottal efficiency and voice quality. This gap is even greater in studies that assess the numerical count technique. I believe that both the phonation test as the count will vary and not only count as asked in other languages. I believe the two tests vary in the same way vital capacity varies depending on the age, height, race, color and weight, unless patients have problems in voice or some deficiency in the glottis or upper airways. It would be very interesting to make a new research involving other countries and languages, and examine whether these our doubts will remain. Brazil is considered a country with a very important race mixing.

2. The normal values found by $\mathrm{Dr}$. Olsen ${ }^{2}$ were counting in English to $100+/-20$ in normal physician volunteers, all of whom were likely Caucasian, male, young \& at that time the average height of a man was $178 \mathrm{~cm}$ (very close to your value). The minimum MPT was 18 seconds.

The findings by Dr. Olsen ${ }^{2}$ are actually larger for the count and lower for MPT compared to ours. In his study, volunteers were excluded who practiced sport or who were singing lessons? Age was the same as ours? We found your question very interesting and we believe that if we compare the populations we do not know if we would find results to those already found. In this regard, do you think the only thing that differs from the two studies is the race? Do you think that over the years the population in your area has changed something? Miscegenation? Would we find the same result today? The MPT, What was the phoneme used by him? The /a/ and the numerical count? We honestly do not believe that these tests would give different results in a possible new research. What we believe are that if a variable range higher in one country to another would have the same behavior. It seems that appeared more 
questions than answers in this matter, but as we feel more encouraged to study the matter.

We would need to see if controlling these variables (age, weight, height, gender, exclusion of singers and wind instrument players and the glottis or disorders of the upper airways) and leaving only the race we would have values as different as these presented and then we could think of establishing a possible pattern in different countries. In our results ${ }^{1}$ and young healthy subjects counted $55.07 \pm 15,693$ men and 50.49 \pm 14.729 women, so we are very surprised with the results found by Dr. Olsen².

In a small trial now, I could not count more than 40 , which left me a question, were they not athletes or played blowing equipment? However, the phoneme of our volunteers was $27.16 \pm 9.133$ for men and $20.68 \pm$ 6.703 for women.

3. We have found that Asians and Afro-Americans tend to have SVC, Forced expiratory volume (FEV) values between 85 \& $90 \%$ of Crapo's ${ }^{3,4}$ values for Caucasians, but these adjustments are probably not important for trending or estimating since values to determine disability would need be determined on precise instruments. I don't recall how broad-cultural Brazilian values compare to Crapo ${ }^{3,4}$.

The SVC values for Brazilians were evaluated by Pereira ${ }^{7}$, with values also considered minor and exclusive equations for Brazilians. In the case of our research, we used the pure SVC parameter without any equation.

4. Another issue relates to vocal cord function. Young people generally have normal VC function. However, I have developed presbyvocalis with aging with weak muscles of phonation, which prevents full closure. I imagine the quantum of air per second is related to the space between the cords. In my own case, I can only phonate for 16 seconds, but can count to 100 or more. In older patients, therefore, it might be wise to do both tests.

We are currently carrying out research on repeatability of these techniques considering the gold standard the SVC by Spiro ${ }^{8}$. From the analysis of these new findings in healthy subjects, we observed an excellent repeatability both between different examiners and in the same examiner after a week. From this new research, we can evaluate the minimum detectable change and the standard error of measurement in all tests and compare them with the gold standard. We believe this would be very important to assess whether a patient is indicating an improvement in the treatment or else a worsening of function. From your report, we feel more motivated to study this technique and we think that TB has much to study as reported by you. It would be good to study these techniques in these patients and mainly functional limitation, which may occur from a consequence of this disease as a pleural effusion, pneumonia or other dysfunction caused by TB. That the discussion related to the psychological state of not using a specific equipment and so as not to contaminate the device also made me very motivated.

As discussed, it seems that there is still a lot of questions about the subject, but I believe we are working in the right way. It would be good to evaluate these techniques in other languages and countries, and study them in different diseases and functional limitations that they leave in lung function.

\section{Best regards}

\section{Marco Valois}

Cardiopulmonary physiotherapy department

University of Penambuco

\section{REFERÊNCIAS}

1. Lima DCB, Palmeira AC, Costa EC, Mesquita FOS, Andrade FMD, Júnior MAVC. Correlation between slow vital capacity and the maximum phonation time in healthy adults. Rev. CEFAC. 2014;16(2):592-7.

2. Olsen CR. The match test. A measure of ventilatory function. Am Rev Respir Dis.1962;86:37-40.

3. Crapo RO, Morris AH, Gardner RM. Reference spirometric values using techniques and equipment that meet ATS recommendations. Am Rev Respir Dis. 1981;123(6):659-64.

4. Crapo RO, Jensen RL, Oyunchimeg M, Tsh T, Duwayne Schmidt C. Differences in spirometry reference values: a statistical comparison of a Mongolian and a Caucasian study. Eur Respir J. 1999;13(3):606-9.

5. Palmeira AC, Araújo RC, Escossio AL, Sarinho SW, Rizzo JA, Andrade FMD, et al .Use of the technique of counting numbers as a predictor of slow vital capacity in hospitalized individuals. Rev. CEFAC. 2015;17(2):559-65 
6. Cardoso NF, Araujo RC, Palmeira AL, Mesquita FOS, Andrade FMD, Correia Júnior MAV. Correlação entre o tempo máximo de fonação e a capacidade vital lenta em indivíduos hospitalizados. ASSOBRAFIR Ciência. 2013;4(3):9-17.

7. Pereira CA. I Consenso Brasileiro sobre espirometria. Jornal Brasileiro de Pneumologia. 1996;22(3):105-64.

8. Correia Junior MAV, Costa EC, Andrade FM, Araujo RC, Rizzo JÁ, Sarinho ESC et al. Reliability of phonation maximum time and capacity in slow vital healthy subjects. In: 25th European Respiratory Society International Congress, 2015, Amsterdam. Eur Respir J. 2015;46(Suppl. 59):PA4200. 